\title{
DIALYSIS - AN OVERVIEW
}

\author{
Mrs. M. VEGUNA RANI, \\ Research Scholar, Medical Surgical Nursing, Vinayaka Missions Research Foundation (Deemed to be University), Salem. \\ Mrs. Dr.K.KAMALA, \\ Principal, Vinayaka Missions College of Nursing, Vinayaka Missions Research Foundation (Deemed to be University), Salem.
}

Abstract: People with failed or damaged kidneys may have difficulty eliminating waste and unwanted water from the blood. Dialysis is an artificial way of carrying out this process. Dialysis substitutes the natural work of the kidneys, so it is also known as renal replacement therapy (RRT).Healthy kidneys regulate the body's levels of water and minerals and remove waste. The kidneys also secrete certain products that are important in metabolism, but dialysis cannot do this. A person who has lost 85 to $90 \%$ of their kidney function will be a likely candidate for dialysis.

\section{Keywords: Dialysis, Metabolism, Renal failure}

\section{INTRODUCTION:}

Dialysis is the process used to remove fluid and waste products from the body when the kidneys are unable to do so, because of impaired function or when toxins or poisons must be removed immediately, to prevent damage. Dialysis used in renal failure remove toxic substance and body wastes normally excreted by healthy kidneys.

\section{DEFINITION:}

Dialysis is the movement of fluid and molecules across a semi permeable membrane from one compartment to another.

\section{PURPOSES:}

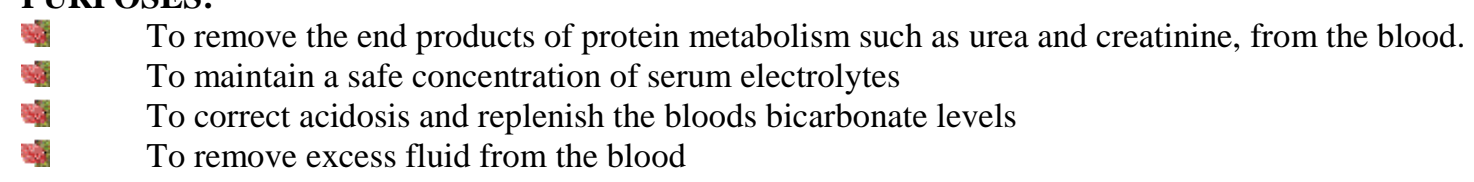

\section{PRINCIPLES:}

\section{* DIFFUSION:}

It is the movement of solutes from an area of greater concentration to an area of lesser concentration.

* OSMOSIS:

It is the movement of fluid an area of an area of lesser to an area of greater concentration of solutes.

* UltRA FILTRATION:

It results were there is osmotic gradient or pressure gradient across the membrane. Excess fluid is removed by increasing the osmolarity of the dialysate with the addition of glucose.

\section{TYPES OF DIALYSIS:}

* Peritoneal dialysis

* hemo dialysis

$*$

\section{PERITONEAL DIALYSIS:}

MEANING:

It involves repeated cycle of instilling dialysate in to the peritoneal cavity, allowing time for substance exchange and then removing the dialysate.

\section{INDICATION:}

* Renal failure

* Who are unable or unwilling to undergo hemo dialysis or renal transplantation

* Patient who are susceptible to the rapid fluid, electrolyte are metabolic changes that occur during hemo dialysis.

* Those who may be risk for side effects of systemic use of heparin.

* Severe hypertension, congestive heart failure and pulmonary oedema not responding to usual treatment regimen.

\section{TYPES:}

$>\quad$ Continuous ambulatory dialysis
$\quad$ Automated peritoneal dialysis 


\section{CONTINUOUS AMBULATORY PERITONEAL DIALYSIS:}

In the continuous type of peritoneal dialysis 1.5 to $3.0 \mathrm{~L}$ of dialysate is instilled into the abdomen and left in place for a prescribed period of time. The empty dialysate bag is folded up and carried in a pocket until it is time to drain the dialysate. The bag is then unfolds and placed lower than the insertion site so that fluid drains by gravity flow. When full, the bag is changed and new dialysate is instilled in to the abdomen as the process continues.

In CAPD usually four dialysis cycle used every 24 hours, including 8 hours dwell overnight.

\section{AUTOMATED PERITONEAL DIALYSIS:}

Automated peritoneal dialysis necessitates use of peritoneal cycling machine. This method can be performed as continuous cyclic, intermittent or nightly intermittent peritoneal dialysis.

\section{CONTINUOUS CYCLIC PERITONEAL DIALYSIS:}

In this variation, there are usually three cycles at night and a cycle with an 8 hour dwell in the morning. The advantage of this procedure is that the peritoneal catheter is opened only for the time of procedures, which reduce the risk of infection.

INTERMITTENT PERITONEAL DIALYSIS:

Dialysis is performed for 10 to 14 hours; 3 to 4 times a week by the same peritoneal cycling machine is a continuous cyclic peritoneal dialysis.

\section{NIGHTLY INTERMITTENT PERITONEAL DIALYSIS:}

Dialysis is performed for 8 to 12 hours each night with no day time dwells.

\section{PREPARATION OF PATIENT PERITONEAL DIALYSIS:}

$\checkmark \quad$ Explain the procedure to the patient and obtained a signed consent

$\checkmark \quad$ Baseline vital signs, weight and serum electrolyte levels are obtained and recorded

$\checkmark \quad$ Emptying the bladder and bowel may be indicated to minimize the risk of puncture of internal organs

$\checkmark \quad$ Assess the patient anxiety about the procedure and to provide support and instruction.

\section{PREPARATION OF THE EQUIPMENT:}

$\checkmark \quad$ Nurse consult with the physician to determine the concentration of dialysing to be used and the medications to be added to the dialysate and assemble the equipment

$\checkmark \quad$ Heparin may be added to prevent fibrin clot formation

$\checkmark \quad$ Potassium chloride may be prescribed to treat hyperkalemia

$\checkmark \quad$ Antibiotics may be added to treat peritonitis

$\checkmark \quad$ Warm the dialysate to body temperature

$\checkmark \quad$ The administration set and tubing are assembled

$\checkmark \quad$ The tube is filled with prepared dialysate fluid to reduce the air entering.

\section{PERITONEAL CATHETER AND ITS INSERTION:}

Soft catheters are inserted through the abdominal wall.

\section{TENCKHOFF:}

It is made of silicone rubber tubing. The catheter are about $60 \mathrm{~cm}$ long and have two Dacron cuffs on the subcutaneous and peritoneal portion of catheter that act as a anchors and prevent the migration of micro organisms down the shaft from the skin within a few weeks, fibrous tissue grown into the Dacron cuff holding the catheter in place and preventing bacterial penetration into the peritoneal cavity. There are two types of catheter used.

* Bent neck, curled catheters

- Disk catheters

\section{TECHNIQUE:}

The technique for catheter placement varies.

\section{NON SURGICAL APPROACH:}

An area approximately $2 \mathrm{~cm}$ below the umbilicus numbed with and local anaesthesia and a small stab wound is made.

$>\quad$ A catheter is inserted and abdomen is distended with dialysis solution

$>\quad$ A catheter place in to the peritoneal cavity

\section{SURGICAL APPROACH:}

A midline umbilical incision is made and a small puncture is made to one side of and below this incision. 
$>\quad$ Distal end of the catheter is placed in the peritoneum and it is tunneled under the skin in to the puncture site

$>\quad$ After catheter is inserted the skin is cleaned with an antiseptic solution, and a sterile dressing is applied.

$>\quad$ A catheter is connected to a sterile tubing system and secure to the abdomen with tape

$>\quad$ A catheter is irrigated immediately with heparinised dialysate $(500 \mathrm{ml})$ to clear it

$>\quad$ A the irrigation may continue for 12 to 24 hours using small volume of dialysate

$>\quad$ Before starting peritoneal dialysis it is preferable to allow a weighting period of 7 to 14 days for proper healing of catheter incision site and for tissue to grow into the cuffs.

$>\quad$ Once the catheter incision site is healed, clean a shower and then pat the catheter and exit the site dry

Daily catheter care includes application antiseptic solution and clean dressing as well as examination of catheter site for the signs of infection.

\title{
DIALYSIS SOLUTION:
}

One or two plastic bags (dianeal, inpersol) with glucose concentration of $1.5 \%, 2.5 \%$ and $4.25 \%$ the dialysate combination is similar to that of plasma. The dialysate solution is warmed to body temperature to increase peritoneal clearance, prevent hypothermia and enhance of comfort.

\section{PHASES OF PERITONEAL CYCLE:}

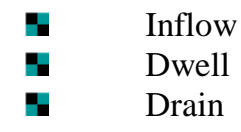

INFLOW:

Solution is infused through the catheter over about 10 minutes. After the solution has been inferred the inflow clamp is closed before air enters the tubing.

\section{DWELL:}

The dwell phase or equilibrium, diffusion and osmosis occur between the patient's blood and the peritoneal cavity. The duration of dwell time can lasts 20 to 30 minutes to 8 or more hours, depend on the method of peritoneal dialysis.

\section{DRAIN:}

Drain time may take 15 to 30 minutes and may be facilitated by gently massaging the abdomen or changing the position.

The cycle start again with the infusion a period of 30 to 50 minutes is required to complete and exchange.

\author{
COMPLICATIONS: \\ $\checkmark \quad$ Peritonitis \\ $\checkmark \quad$ Bleeding \\ $\checkmark \quad$ Respiratory difficult \\ $\checkmark \quad$ Abdominal pain \\ $\checkmark \quad$ Leakage \\ $\checkmark \quad$ Constipation \\ $\checkmark \quad$ Low serum albumin
}

\section{HEMO DIALYSIS:}

DEFINITION:

A synthetic semi permeable membrane replaces the renal glomeruli and tubercles act as filter of impaired kidneys.

\section{VASCULAR ACCESS SITES:}

\section{FISTULA}

Fistula is created surgically by connecting a joining an artery to vein either side or end side (AV Fistula). It takes 4-6 weeks to mature before needy to use.

\section{2. $\quad$ GRAFT:}

A graft is created by suturing a piece of bovine artery or vein, heterograft material or saphenous vein graft into the patient's own vessel. Graft is placed in forearm, upper arm or upper thigh.

\section{SHUNT:}

The shunt consists of a U- shaped silastic tube divided at the midpoint and each of the two ends is placed in an artery and vein. External shunts were used in the past, but now rarely used due to numerous complications associated with them. 


\section{TEMPORARY VASCULAR ACCESS:}

In some situations, immediate vascular access is required, percutaneous cannulation of the internal jugular or femoral vein is performed. A flexible Teflon, silicon rubber or poly urethane catheter is inserted into one of these large veins and provides access to circulation without surgery.

Temporary catheter in the jugular or subclavian veins can be left in place for 1 to 3 weeks, femoral vein cannulas can remain for up to 1 week.

\section{HEMO DIALYSIS SYSTEM:}

In hemo dialysis system, the blood is removed via a needle inserted in a fistula or via lumen catheter. It is propelled to the dialyzer by heparin pump. Heparin is infused either as blows before dialysis or through a heparin pump continuously to prevent clotting. Dialysate is pumped in and flows in to the opposite direction of the blood. The dialyzed blood is returned to the patient through the second needle on lumen catheter. Old dialysate and ultra filtration are drained and discarded.

\section{TYPES OF HEMODIALYSIS: \\ * Home hemo dialysis \\ * Hemo dialysis \\ * Continuous Arteriovenous hemofiltration}

\section{DIALYZERS:}

Dialyzers are a long plastic cartridge that contains thousands of parallel hallows tubes or fibres. The blood is pumped into the top of the cartridge and is dispersed into the top of the cartridge and is dispersed into all of the fibres.

\section{HEMO DIALYSIS SCHEDULE:}

It varies with the size of client, type of dialyzer used, the rate of blood flow, personal preference of the client and other factors.

\section{THERAPEUTIC EFFECTS OF HEMO DIALYSIS:}

\section{* Clear the waste product from the body}

* Restore the fluid and electrolyte balance

\section{MANAGEMENT:}

* During procedure promote patient comfort

* Meet the psychological considerations

* Dietary intake of electrolyte may be encouraged or restricted

* Restrict potassium

* Advice to continue the medications.

\section{COMPLICATIONS:}

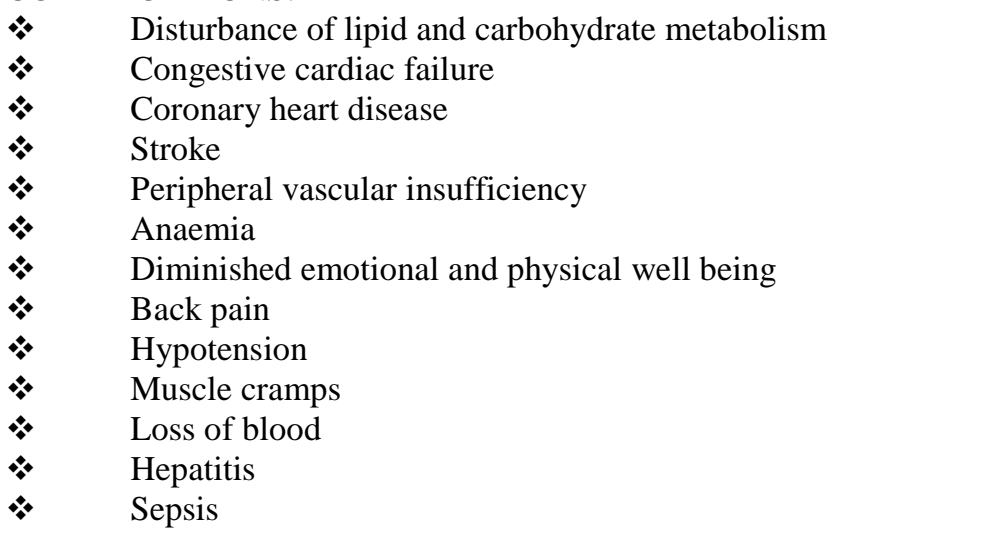

\section{CURRENT TRENDS RECOMMENDATIONS FOR PROVIDING DIALYSIS TREATMENT TO PATIENTS WITH INFECTED DISEASE}

The following recommendations take into consideration recent knowledge about update infection-control strategies for dialyzing patients with infected disease:

1. Procedures for environmental control and for disinfection and sterilization of hemo dialysis machines have been described. The hemo dialysis machine pumps dialysis fluid into the dialyzer (artificial kidney) where circulating blood from the patient is separated from the dialysis fluid by a membrane. The dialyzer, along with the associated blood lines, is disposable. Strategies for disinfecting the dialysis fluid pathways of the hemo dialysis machine are targeted to control bacterial contamination and generally consist of using about 500-750 ppm of sodium hypochlorite for 30-40 minutes or 1.5\%-2.0\% formaldehyde overnight. In addition, several chemical germicides 
formulated to disinfect dialysis machines are commercially available. None of these protocols or procedures need to be altered after dialyzing patients infected with HTLV-III/LAV. Chemical germicides used for disinfection and sterilization of devices in the dialysis centre are effective against HTLV-III/LAV.

2. Patients infected with HTLV-III/LAV can be dialyzed by either hemo dialysis or peritoneal dialysis and do not need to be isolated from other patients. The type of dialysis treatment (i.e., hemo dialysis or peritoneal dialysis) should be based on the needs of the patient. The dialyzer may be discarded after each use. Alternatively, centers that have dialyzer-reuse programs, in which a specific dialyzer is issued to a specific patient, removed, cleaned, disinfected, and reused several times on the same patient only, may include HTLV-III/LAV-infected patients in the dialyzer-reuse program. An individual dialyzer must never be used on more than one patient. 3. Standard infection-control strategies that are used routinely in dialysis units for all dialysis patients and personnel should be used to prevent HTLV-III/LAV transmission. Specifically, these strategies include blood precautions and barrier techniques, such as the use of gloves, gowns, and hand washing techniques that have been described elsewhere.

\section{REFERENCES:}

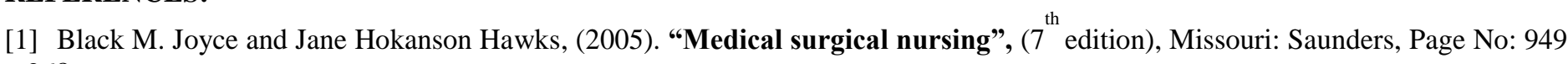
-968 .

[2] Lewis, et. al., (2007). "Medical surgical nursing", $\left(7^{\text {th) }}\right.$ edition), Missouri: Mosby, Page No: 1204 -1216.

[3] Phipps, Long and Woods, (1999). "Shaffer's Medical Surgical Nursing", (7th edition), New Delhi: B.I Publications Pvt. Ltd., Page No: 643-647.

[4] Smeltzer C. Suzanne and Bare G., Brenda, (2004). "Brunner and suddarth's text book of Medical surgical Nursing", (10 edition), Philadelphia :Lippincott Williams and Wilkins, Page No:1326-40

[5] htt/ptt/:www.dialysis.com

[6] htt/ptt/:emedicine.medscape.com

[7] http ://www.ncbi.nlm.nih.gov/pubmed

[8] http ://www. nlm. nib. gov/medcineplus

[9] http ://www.emedicine. medscape.com

[10] http ://www. Nephrology channel. Com 